\title{
A Case of a Primary Branchiogenic Carcinoma with a Synchronous Tonsil Squamous Cell Carcinoma
}

\author{
Byungjin Kang, Hwaejoon Jung, Su-Jong Kim, and Jeong-Soo Woo \\ Department of Otorhinolaryngology-Head and Neck Surgery, Korea University College of Medicine, Seoul, Korea
}

\author{
편도 편평세포 암종과 동시에 발견된 원발성 새열낭종 기원 암종 1예 \\ 강병진 · 정회준 · 김수종 · 우정수 \\ 고려대학교 의과대학 이비인후-두경부외과학교실
}

\author{
Received August 2, 2016 \\ Revised September 23, 2016 \\ Accepted September 28, 2016 \\ Address for correspondence \\ Jeong-Soo Woo, MD, PhD \\ Department of Otorhinolaryngology- \\ Head and Neck Surgery, \\ Korea University \\ College of Medicine, \\ 148 Gurodong-ro, Guro-gu, \\ Seoul 08308, Korea \\ Tel +82-2-2626-3187 \\ Fax $+82-2-868-0475$ \\ E-mail diakonos@korea.ac.kr
}

Branchiogenic carcinoma (BC), which is defined as squamous cell carcinoma arising from a branchial cyst, was first described by Volkmann in 1882. This rare disease is regarded as hypothetical, and remains a controversial disease entity. Among the diagnostic criteria of $\mathrm{BC}$, the key point is the histologic demonstration of a cancer developing from the wall of an epithelial-lined cyst in the lateral site of the neck. In previous literature, many authors argued that this malignancy is actually cystic metastasis from oropharyngeal squamous cell carcinoma. We report a case of a 49 -year-old female who was diagnosed as a primary BC patient with a synchronous tonsillar squamous cell carcinoma. Although this case did not meet the traditional diagnostic criteria because of existing tonsil cancer, we could diagnose these diseases as primary malignancies, since the transition zone was clearly seen, and there was no lymph node component in the histopathologic examination.

Korean J Otorhinolaryngol-Head Neck Surg 2016;59(12):856-9

Key Words Branchioma · Carcinoma · Multiple primary neoplasm · Squamous cells · Tonsillar neoplasms.

\section{Introduction}

Branchiogenic carcinoma (BC), which is defined as squamous cell carcinoma arising from a branchial cleft cyst, was first described by Von Volkmann in 1882. ${ }^{1)}$ The diagnostic criteria of $\mathrm{BC}$ was first proposed in the study of Martin, et $\mathrm{al}^{2)}$ in 1950, and was partially revised by Khafif, et al. ${ }^{3)}$ in 1989. Among the diagnostic criteria of BC, the key point is the histologic demonstration of a cancer developing from the wall of an epithelial-lined cyst in the lateral site of the neck. However, in fact, due to particular diagnostic criteria, BC is rarely diagnosed. Some authors argue that the diagnosis of this disease is theoretical and skeptical. Therefore, diagnosis itself remains controversial until recently.

Micheau, et al. ${ }^{4)}$ argued that $\mathrm{BC}$ is the misdiagnosis of cys- tic metastasis, developed in a primary occult lesion of the tonsil, rather than a real disease. Therefore, it is currently difficult to admit the co-existence of $\mathrm{BC}$ with tonsil cancer. However, the authors examined the case of a 49-year-old female patient who was admitted due to a left lateral neck mass, and was diagnosed with $\mathrm{BC}$ with a squamous cell carcinoma of the left tonsil. We reported the case with a literature review.

\section{Case}

A 49-year-old female patient visited the outpatient clinic of our institution after a left lateral neck mass was found two weeks earlier. On a comprehensive physical examination, a fluctuating, mobile mass at level IIA of the left neck was 

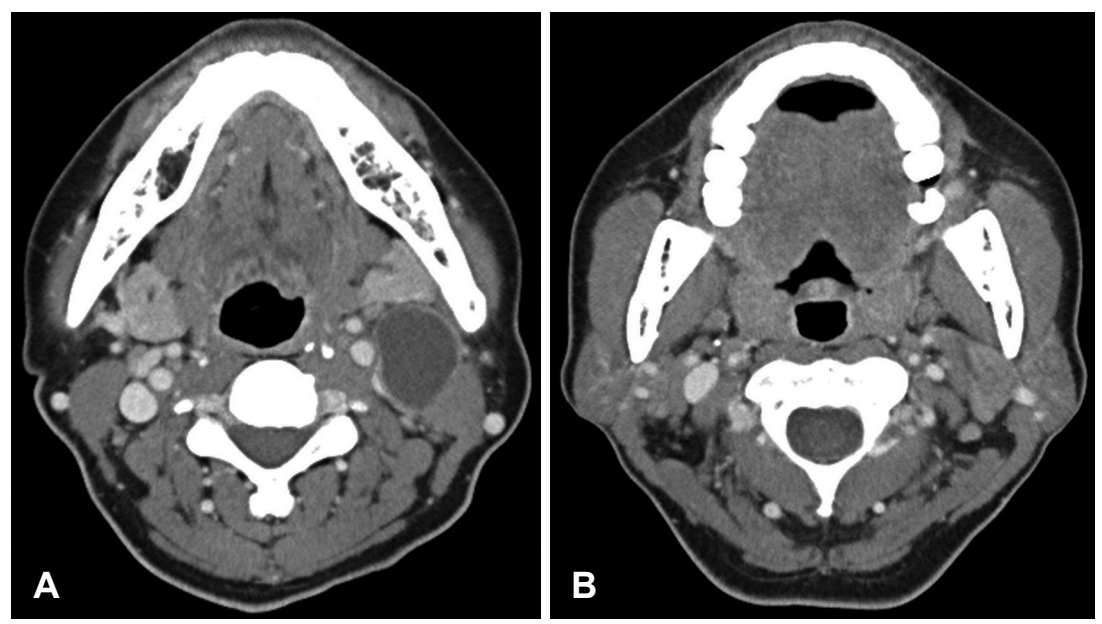

Fig. 1. Contrast-enhanced computed tomography $(\mathrm{CT})$ axial scan images of the patient. Image showing $2.8 \times 2.0 \times 3.3 \mathrm{~cm}$ in size, rim enhancing cystic mass in the posterolateral aspect to the left submandibular gland (A). Image showing mild hypertrophy without any definite lesion in both palatine tonsils (B).

palpated without tenderness, and there was no other unusual finding. She did not have a smoking history, and there was nothing significant in her surgery and medication history.

On the ultrasound of neck region, a well-defined cervical mass with a size of $2.9 \times 2.2 \mathrm{~cm}$ was observed in the posterolateral aspect to the left submandibular gland, and in the anteromedial aspect to the left sternocleidomastoid muscle. On the computed tomography (CT), a cystic mass with a size of $2.8 \times 2.0 \times 3.3 \mathrm{~cm}$ was observed in the same location (Fig. 1A). Abnormal findings were not observed in Waldeyer's ring, and there was no finding of an increase in the size of the cervical lymph node on the physical examination and CT scan (Fig. 1B). Ultrasound-guided fine needle aspiration cytology was performed on the cystic mass in the left neck. There was no malignant finding on the cytology, and it revealed a benign cystic lesion. Based on the location of the lesion, the result of the cytology, and imaging findings, we clinically diagnosed it as a branchial cleft cyst, and performed mass resection.

Resected specimen was grossly observed as a whitish cystic mass with a size of $2.7 \mathrm{~cm}$ in the long axis (Fig. 2). The histopathologic diagnosis of the tumor was squamous cell carcinoma, most probably arising in branchial cleft cyst. Ten lymph nodes were also noted in the surrounding tissue, which was resected along the main mass. However, there was no malignant metastasis. Microscopically, it had a form of lymphoepithelial cyst with a normal squamous cell layer, which is a typical branchial cyst finding, and there was partial invasion. Since there was a definite normal squamous cell layer, we could confirm that the mass was not a lymph node, and a necrotic portion was not detected (Fig. 3A). Because a transition zone between benign and invasive lesions was observed, we could infer that squamous cell carcinoma developed in the epithe-

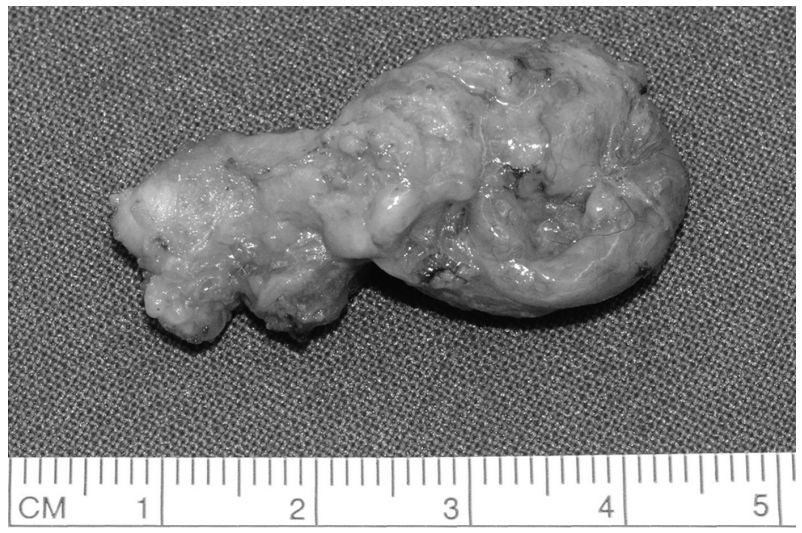

Fig. 2. Specimen after excision of cervical mass. A whitish friable, $2.7 \mathrm{~cm}$ size, papillary mass was noted.

lial cell of this part (Fig. 3B). Tumor cells showed hyperchromatism, pleomorphism, and atypism. The deposition of lymphocytes was shown on the cystic wall, however the structures of the lymph nodes such as the peripheral lobulation, internodular trabecule, and perinodular sinuses were not observed.

The patient underwent further endoscopy for the oral cavity, oral pharynx, nasopharynx and hypopharynx with upper and lower gastrointestinal endoscopy. Furthermore, MRI on the head and neck and Torso PET-CT scan were conducted. Nevertheless, no site was suspected as a primary site during evaluation. The maximum standardized uptake values (maxSUV) of left tonsil was 6.81, relatively high. However, maxSUV of right tonsil was 6.65 , similar to that of left side. Diagnostic tonsillectomy was performed on both sides along with panendoscopic biopsy under general anesthesia. The histopathologic examination showed that lesions were not found on both piriform sinus, tongue base, nasopharynx, and right tonsil. However, in the left tonsil, a well-differentiated squamous cell carcinoma with a size of $1.5 \times 0.8 \times 0.5 \mathrm{~cm}$ 
was found (Fig. 3C). The invasion to the deep resection margin was confirmed, and transoral lateral oropharyngectomy was additionally performed on the left side. In the final histopathologic result, a well-differentiated squamous cell carcinoma was confirmed without an invasion of the resection margin. However, since the safety margin of the inferior re-
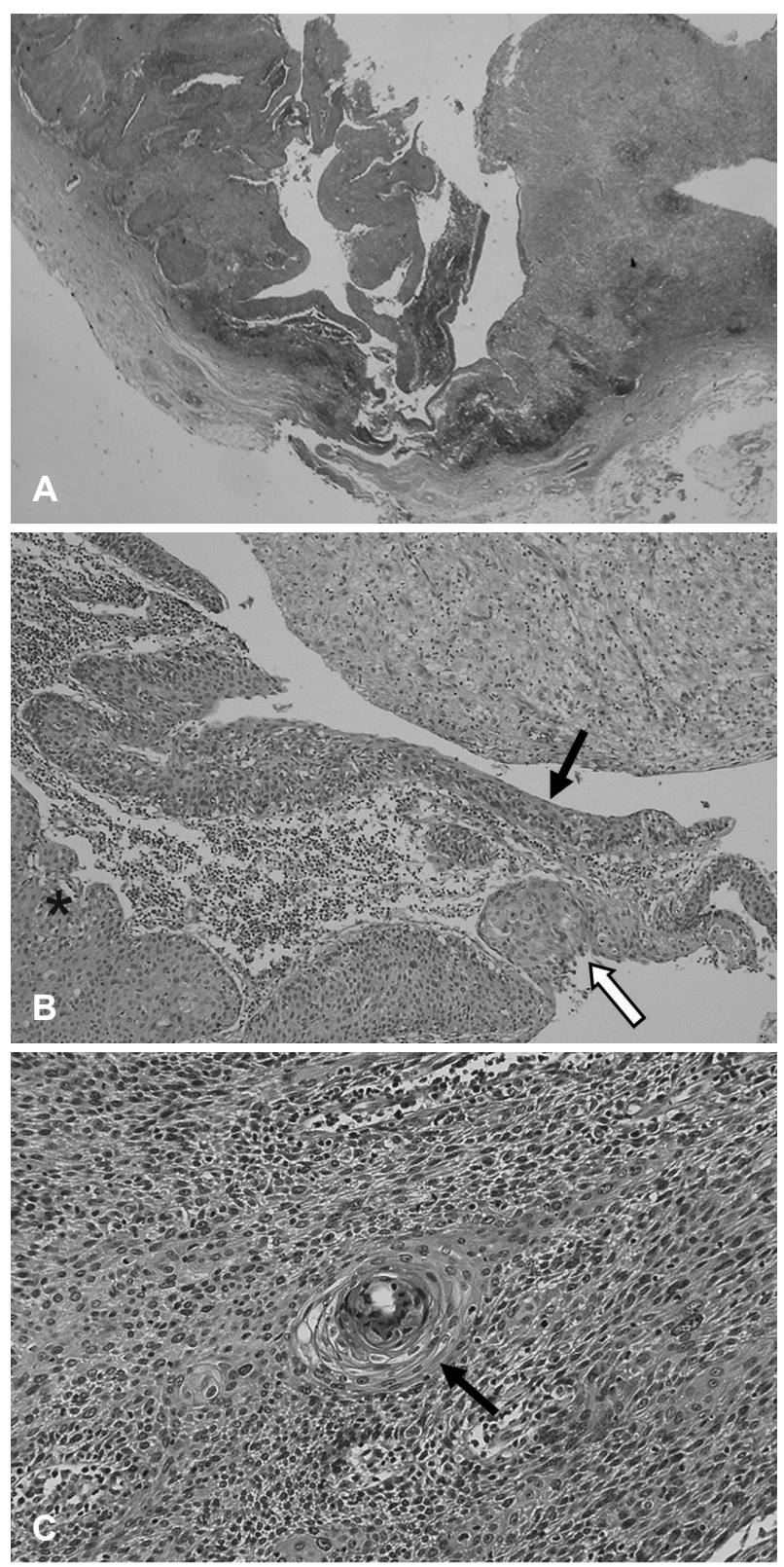

Fig. 3. Histopathologic finding of the branchiogenic carcinoma, overview ( $\times 12.5$, H\&E stain). The lymphoepithelial cyst with normal squamous cell lining was noted and the necrotic portion was not found. Histopathologic finding of the branchiogenic carcinoma, magnified ( $\times 200$, H\&E stain) $(A)$. The transition zone along the benign epithelium (black arrow), carcinoma in situ (white arrow) and invasive lesion (asterisk) was found. Histopathologic finding of the left tonsil cancer ( $\times 400, \mathrm{H} \& \mathrm{E}$ stain) $(B)$. The lesion was consistent with squamous cell carcinoma, including whirling keratin pearl (black arrow) (C). section was narrow, at $1 \mathrm{~mm}, 30$ sessions of additional radiation therapy with $200 \mathrm{cGy}$ were conducted. Additional treatment, such as radiation therapy, was not administered on the neck lesion. There was no evidence of relapse until 2 years after surgery. The patient is undergoing regular follow-up.

\section{Discussion}

A cystic mass arising in lateral neck are commonly benign lesion including branchial cleft cyst. ${ }^{5}$ However, a malignant lesion including solitary cystic metastases of nasopharyngeal, tonsillar, papillary thyroid carcinoma, and rarely primary $\mathrm{BC}$ should be considered in patients with old age. ${ }^{6.7)}$ Therefore, strict diagnostic criteria are necessary to distinguish primary $\mathrm{BC}$ and cystic metastases of other head and neck cancer. Martin, et al. ${ }^{2)}$ first proposed the diagnostic criteria of this disease in 1950, as follows. ${ }^{8}$ 1) The location of the tumor along the anatomic region of the anterior border of the sternocleidomastoid muscle; 2) The histologic appearance of the tumor consistent with tissues from the branchial vestige; 3) No evidence of a primary cancer source during a minimum of 5 years of follow-up; 4) The histological evidence of carcinoma developing in the wall of an epithelial-lined cyst situated in the lateral neck. Khafif, et al. ${ }^{3)}$ modified the previous diagnostic criteria in 1989. To fulfill the five-year follow-up period, the diagnosis on the potential primary site must not be delayed. The progression of the hidden primary site might be stopped due to additional radiation therapy after surgery, and consequently it might not be found. Therefore, the third criterion was excluded from the criteria proposed by Martin, et al., ${ }^{2)}$ while two other criteria were added. 1) The transition zone from the normal squamous epithelial cell of the cyst to squamous cell carcinoma must be identified; 2) It can be diagnosed when the primary malignant tumor is not found even after a thorough assessment. However, many authors, including Micheau, et al.,") argue that $\mathrm{BC}$ is not a definite disease, and it might be a misdiagnosis of the cystic lymph node metastasis of primary tonsil cancer. ${ }^{8-10)}$ This controversy arises because cervical metastasis developing in the upper aerodigestive tract is relatively common, the onset locations of jugular lymph nodes and branchial cleft cyst are similar, and it is difficult to distinguish histologically the cystic change in metastatic lymph node from BC. Therefore, no clear conclusion has been made until now. ${ }^{11)}$

In this case, the left neck mass was initially diagnosed as second branchial cleft cyst, squamous cell carcinoma was 
diagnosed on the biopsy after mass resection, and squamous cell carcinoma was also confirmed in the left tonsil. Therefore, it does not meet the criteria suggested by Khafif, et al. ${ }^{3)}$ In general, it might be reasonable to see a malignant mass in the left neck level IIA as a cystic lymph node metastasis of tonsil cancer. Nevertheless, a normal epithelial cell layer, which is not histologically found in lymph nodes, was observed, and based on this, a definite transition zone connected to dysplasia, carcinoma in situ, and invasive carcinoma exists. Also, characteristic structures normally seen in lymph nodes were not observed. Furthermore, there was no proof of infiltration through vascular or lymphatic vessels in the histopathological review. Therefore, the authors diagnosed this case as double primary cancer of squamous cell carcinoma in the left tonsil and left BC.

Since the establishment of the diagnostic criteria, there have been several cases that satisfied all of criteria. In Japan, approximately 100 cases have been reported, while in Korea, only five cases were confirmed histopathologically. ${ }^{12-15)} \mathrm{We}$ reported a case in which the patient was diagnosed with double primary cancer of BC histologically accompanied with squamous cell carcinoma in the ipsilateral tonsil. Even for carcinoma originating from Waldeyer's ring is confirmed, like in this case, if many cases that emphasize histological diagnosis are reported in the diagnosis of $\mathrm{BC}$, afterward previously known diagnostic criteria can be changed. And the clinical characteristics of this disease that were not previously identified can be discussed more thoroughly.

\section{REFERENCES}

1) Von Volkmann R. Das tiefe branchiogene halskarcinom. Zentralbl
Chir 1882;9:49-63.

2) Martin H, Morfit HM, Ehrlich H. The case for branchiogenic cancer (malignant branchioma). Ann Surg 1950;132(5):867-87.

3) Khafif RA, Prichep R, Minkowitz S. Primary branchiogenic carcinoma. Head Neck 1989;11(2):153-63.

4) Micheau C, Klijanienko J, Luboinski B, Richard J. So-called branchiogenic carcinoma is actually cystic metastases in the neck from a tonsillar primary. Laryngoscope 1990;100(8):878-83.

5) Thompson LD. Diagnostically challenging lesions in head and neck pathology. Eur Arch Otorhinolaryngol 1997;254(8):357-66.

6) Gourin CG, Johnson JT. Incidence of unsuspected metastases in lateral cervical cysts. Laryngoscope 2000;110(10 Pt 1):1637-41.

7) Tegeltija D, Lovrenski A, Panjković M, Marjanov J, Samardzija G, Pejaković N. Carcinoma developing in a branchial cyst. Med Pregl 2013;66(3-4):177-80.

8) Bradley PT, Bradley PJ. Branchial cleft cyst carcinoma: fact or fiction? Curr Opin Otolaryngol Head Neck Surg 2013;21(2):118-23.

9) Singh B, Balwally AN, Sundaram K, Har-El G, Krgin B. Branchial cleft cyst carcinoma: myth or reality? Ann Otol Rhinol Laryngol 1998;107(6):519-24.

10) Jereczek-Fossa BA, Casadio C, Jassem J, Luzzatto F, Viale G, Bruschini $\mathrm{R}$, et al. Branchiogenic carcinoma--conceptual or true clinicopathological entity? Cancer Treat Rev 2005;31(2):106-14.

11) Briggs RD, Pou AM, Schnadig VJ. Cystic metastasis versus branchial cleft carcinoma: a diagnostic challenge. Laryngoscope 2002;112(6): $1010-4$.

12) Saito $T$, Sato $T$, Usui $H$, Hirashita $K$, Asada $K$, Ishibashi K. A case of squamous cell carcinoma arising from branchial cleft cyst. Oral Science Int 2008;5(2):135-40.

13) Kim HC, Hwang IK, Kim BS, Namkung S, Hwang WC. Squamous cell carcinoma arising from second branchial cleft cyst: case report. J Korean Radiol Soc 2003;48(2):127-9.

14) Yang YS, Oh JK, Jeon HS, Hong KH. A cases of primary branchial cleft cyst carcinoma. Korean J Otolaryngol-Head Neck Surg 2004; 47(12):1319-22.

15) Lee JS, Ko YB, Park GC. A case of squamous cell carcinoma arising in a second branchial cleft cyst. Korean J Otorhinolaryngol-Head Neck Surg 2013;56(12):791-4. 